\title{
Procesos de comunicación propia para vivir en armonía con la madre tierra en la comunidad indígena Sumu-Mayangna Fruta de Pan, 2016
}

\author{
Self-communication processes to live in harmony with mother earth in \\ Fruta de Pan, the Sumu-Mayangna indigenous community, 2016
}

\author{
Deysi Audely Chavarría Picado ${ }^{1}$ \\ Letisia Castillo Gómez ${ }^{2}$
}

\section{Resumen}

Esta crianza y recolección de conocimientos fue realizada en la comunidad indígena de Fruta de Pan, perteneciente a los pueblos autóctonos ancestrales denominados sumus, e identificados actualmente como sumu-mayangna, localizada a cuatro kilómetros del municipio de Rosita, Región Autónoma de la Costa Caribe Norte de Nicaragua. Entre los hallazgos encontrados resaltan, que el profundo conocimiento de los fenómenos que ocurren en la tierra, es una experiencia basada en la observación y en los saberes ancestrales de este pueblo, producida por una práctica comunicativa con los espíritus que habitan en cada espacio de la tierra, estableciendo de esa manera una vida armoniosa con el territorio. El estudio evidencia que la lengua de este pueblo está desapareciendo debido a un sistemático proceso de aculturación y, que sus prácticas comunicativas están conectadas a la madre tierra; considerada un ser vivo y dimensional, que comunica sentimientos, reglas y formas de procurar el bienestar, de allí que la vida comunitaria sea indispensable para compartir. Éste es un pueblo cuya fuerza superior radica en los sueños, que les previene de los peligros, o les revela la alegría que está por llegar. Sus alimentos son un arte tradicional.

Palabras clave: Comunicación intercultural; espiritualidad; madre tierra; tierras comunales.

\section{Abstract}

This breeding and gathering of knowledge was carried out in the indigenous community of Fruta de Pan, belonging to the ancestral indigenous peoples called sumus, and currently identified as sumu-mayangna, located four kilometers from Rosita municipality, Autonomous Regions of the North Caribbean Coast, Nicaragua. Among the findings, the profound knowledge of the phenomena that occur on earth is an

\footnotetext{
1 Máster en Comunicación Intercultural con Enfoque de Género. Radio Universidad, Extensión URACCAN Rosita. Email: dchavaria@gmail.com

2 Candidata Doctoral y Máster en Docencia Universitaria. Directora Acádemica de la Universidad de las Regiones Autónomas de la Costa Caribe Nicaragüense (URACCAN). Email: letycuba2001@yahoo.com - ORCID: https://orcid.org/oooo-0002-1585-1049
}

Recibido: 26/02/2018 Aprobado: 28/o8/2018 
experience based on the observation and ancestral knowledge of this people, produced by a communicative practice with the spirits that inhabit each space of the land, establishing in that way a harmonious life with the territory. The study shows that the language of this people is disappearing due to a systematic process of acculturation and that their communicative practices are connected to mother earth, considered a living and dimensional being, that communicates feelings, rules and ways of procuring well-being, hence, community life is essential to share. This is a town whose superior strength lies in dreams, which warns them of dangers, or reveals to them the joy that is to come. Their food is a traditional art.

Keywords: Intercultural communication; spirituality; mother earth; communal lands.

\section{Introducción}

Los procesos de comunicación propia para vivir en armonía con la madre tierra en la comunidad indígena sumu-mayangna Fruta de Pan, ubicada en el municipio de Rosita, en la Región Autónoma de la Costa Caribe Norte de Nicaragua, nace de la preocupación de las y los autóctonos por la venta ilegal de tierras en el territorio.

La cosmovisión sumu-mayangna sobre la tierra es que ella es una madre que se comunica, cuida y alimenta a su familia, lo que conlleva a la conservación de los recursos naturales, hacer prácticas propias de comunicación desde la magia, las oraciones o salmos que son reales (UNESCO, 2012a). Pero contrario a todo lo dicho, en las últimas dos décadas las y los originarios parecen haber olvidado el sentido de resguardo de la naturaleza.

Este fenómeno ocurre producto de la pérdida de identidad de algunos hombres y mujeres originarios de la comunidad sumu-mayangna de Wasakin, quienes desde hace mucho tiempo vienen vendiendo la propiedad comunal y es a principios del 2016, que las autoridades comunales de Colmata, Betania, Fruta de Pan, y Divehi, se enteran de que justo en medio de los bloques de tierra que pertenecen a cada comunidad están acentados mestizos haciendo potrero para el ganado, en abierta alusión al avance de la frontera agrícola.

De acuerdo a información suministrada por Teylor (2016), actualmente más de 300 manzanas de montaña virgen han sido despaladas por grupos de personas que aseguran haber comprado esta parte del territorio comunitario y pese a que se han reunido para dialogar no han logrado acuerdos y las familias sumu-mayangnas están bajo amenazas de muerte por parte de los llamados colonos. La ausencia de identidad se ha visto acelerada también por la pérdida de la lengua nativa, tras los constantes matrimonios mixtos con personas indígenas del grupo miskitu quienes a su vez están siendo colonizados en el pensamiento por la cultura mestiza. 
Esta crianza y recolección de conocimientos representa alternativas viables y eficaces para la madre tierra y será de utilidad para las y los indígenas sumu-mayangnas de Fruta de Pan, porque les consentirá realizar un auto-reconocimiento y revitalizar aspectos propios de sus formas de vida. También se convertirá en un referente para las personas que realicen otros procesos de cultivo crianza y recolección de conocimientos.

La comunicación con la madre tierra es posible en la vida espiritual que existe en ella, sus espíritus transmiten mensajes a través de signos que fueron decodificados por los ancestros, significancia que se convirtieron en la información común de este grupo, quienes producto de este proceso creen que los hijos e hijas de la tierra deben resguardarla.

El camino de la creación, recreación de conocimientos, saberes y prácticas comenzó con la conversación con ancianos de la comunidad, luego se procedió a la armonización de los saberes, siguiendo una secuencia lógica con el enfoque cualitativo en colaboración con el método del interaccionismo simbólico que permitió analizar el desarrollo natural de los sucesos y comprender el proceso de asignación de símbolos con significados a la lengua hablada o escrita y al comportamiento en la interacción social.

Para lograr los objetivos planteados se utilizaron las técnicas del conversatorio propuesto en el CCRISAC, con esto fue posible obtener los saberes desde una visión intergeneracional por medio de la palabra. También se realizaron entrevistas de manera individual a personas claves en la recolección de la cosecha, habiéndolas identificado luego de un muestreo estratégico en el que se incluyó a personas que pertenecen al grupo originario sumu-mayangna, que practican los conocimientos ancestrales inspirados en lo existente en la tierra, ríos, áreas de protección, espacios sagrados y en las realidades anímicas que subsisten en cada planta y área natural.

\section{Revisión de literatura}

Los saberes ancestrales. Los conocimientos de una vida espiritual en la naturaleza y la lectura de los símbolos son las sabidurías de los hombres y mujeres, por los saberes, conocimientos y prácticas encarnados en cada uno, construida en su relación íntima y continua con la Pacha mama-Madre tierra (Muñoz y Romero, 2010).

Comunicación Espiritual. La existencia de personas que se comunican con los espíritus y aseguran que estas personas son escogidos por los dioses supremos de la naturaleza, la que es el centro de todo y es la parte más importante del universo: observa, comprende y comunican las buenas voluntades o su desagrados y que los chamanes interceden ante el mundo sobrenatural y el humano, por tal motivo, se les considera como los sabios y sabias especialistas en comunicarse con otras realidades $\mathrm{u}$ otras dimensiones de diferentes maneras. Chuji (2007) y Agurto y Mescco (2010). 
Comunicación a través de los Sueños. Agurto y Mescco (2010), Gutiérrez et al (2015) y Veughan-Lee (2015) refieren que soñar no es un hecho que carece de significado y significación, sino que es una forma de comunicarnos con los espíritus de la naturaleza y/o de los ancestros. Al interpretar los sueños se encuentran personajes del interior llenos de sabiduría, porque hay lenguajes internos esperando a ser redescubiertos. Por lo que en un sueño encontramos nuestro camino individual en el mundo y realizamos un andar atentos y alertas, para responder a las necesidades de los demás.

Arte tradicional comunicativo. Para Gonzáles (2004) y Pérez y Merino (2014), el arte no pretende agradar a nadie, es expresión, es pensamiento visual, no está hecho para consumirse, más allá de su función social, porque es un vehículo que permite expresar o reflejar la cosmovisión de una persona, a través de los manifestaciones artísticas, el sujeto plasma su representación del mundo y sus valores, por lo que la calidad de su producto está hecho para alguien con rostro, para un ser querido o respetado, para los dioses, para los antepasados, para honrar la tradición del amor a la tierra.

Gastronomía "comida propia". Desde la perspectiva de Delfin (2010), la gastronomía es el arte intangible al preparar una buena comida. Es arte los objetos de uso cotidiano, aquéllos que son elegidos para representar las costumbres de una sociedad en un momento determinado de su historia. Como por ejemplo, la ropa, los instrumentos de carpintería, las armas, la comida.

Práctica cultural lingüística. El planteamiento de De Magdalena (2010), es que la recepción por un pueblo o grupo social de formas de cultura procedentes de otro, que sustituyen de un modo más o menos completo a las propias. De acuerdo con lo observado la transculturación que sufren las y los sumu-mayangnas de esta comunidad, afecta también la identidad individual y colectiva ya que son familias mixtas donde predomina una de las culturas.

\section{Manifestaciones de procesos de comunicación propia para vivir en armonía con la madre tierra}

Cosmovisión. Pérez y Merino (2014), plantean que la cosmovisión se fundamenta en su relación con la madre tierra y la naturaleza, sabiendo leer las señales del clima, conocer los secretos de la tierra y las montañas, respetar y aprender de la selva, sacar agua de los desiertos y las zonas de conservación.

Danza: Para Delfin (2010) y la UNESCO (2012b), la danza representa el vínculo que se establece con las fuerzas sobrenaturales y con lo dioses del grupo en cuestión. Las comunidades indígenas danzan por una manifestación de los saberes obtenidos de la madre tierra. La danza de los sapos que anuncian el invierno croando y saltando, lo que es señal de que llega también el periodo de siembra (entre abril y mayo). Significa 
para nuestros ancestros, la esperanza y renovación de vida, de buenos tiempos, de abundancia, de fertilidad.

Resistencia indígena. De acuerdo a Arrobo (2005), para mantener la vida, las identidades colectivas y los valores comunitarios, los pueblos deben resistirse a ceder su territorio y su cultura, igual que cuidar los espacios de comunicación indígena porque es constitutiva del sujeto social indígena y de sus expresiones simbólicas.

Defensa del territorio indigne. La postura de Jarquín y Moreno (2014), es que la vivencia con la madre tierra a través de la espiritualidad permite a las y los indígenas que aparezcan las leyendas. Las mismas son parte de las enseñanzas y aprendizajes en el uso y relación con la Madre Tierra así como la historia y las creencias de los pueblos.

\section{Estrategias de revitalización y dinamización de las prácticas propias de comunicación propia para vivir en armonía con la madre tierra}

Descolonizar el pensamiento. Democratizar la palabra para democratizar esa sociedad injusta a la que le quieren acostumbrar los dueños del dinero y del poder. En las radios comunitarias es donde se ve este tipo de movimiento por la lucha de sus derechos, por el entusiasmo de buscar mejoría para su pueblo. La programación de la emisora debe ser personalizada por las organizaciones indígenas, para la revitalización de la identidad cultural y la autoestima de los pueblos y nacionalidades. Las principales actividades que desde la radio se pueden promueven son la organización, la movilización social, la protesta, la defensa de los territorios, la interculturalidad y la lengua. (Gómez 2013; Chuji 2007).

\section{Materiales y métodos}

El caminar de la crianza y recolección de estos conocimientos se hizo desde una perspectiva de construcción colectiva, como un camino sugerido por el CCRISAC (2015), y que en la práctica se tradujo en una importante cooperación humanitaria de personas interesadas en aportar sus sueños en una cosecha valiosa y abundante. Todas estas ideas se fueron escribiendo hasta obtener el estudio construido.

El análisis del contacto y la armonía de los saberes fue parte del camino recorrido que nos permitió diferenciar los diferentes senderos que existen para echar a andar este método que se edificó desde la convivencia, como una actividad fructífera y amena que permitió un diálogo verdadero. Entre las acciones propuestas por la propia comunidad están, una caminata con el anciano, así que mientras recorríamos la comunidad, las palabras sabias del anciano y líder, afloraron. 


\section{Enfoque}

La presente crianza del conocimiento, se realizó bajo el enfoque cualitativo, que permitió analizar el desarrollo natural de las practicas comunicativas de hombres y mujeres mayangnas para la defensa de la tierra, según la recomendación de Hernández y Baptista, (2015, p.9) citando a (Corbetta, 2003). Con este enfoque, no hay manipulación ni estimulación con respecto a la realidad, además permite estudiar a las culturas y entender las problemáticas sociales, características importantes para que se llevará a cabo el análisis de las formas propias de comunicación de la comunidad de Fruta De Pan.

\section{Método}

El método seguido fue el interaccionismo simbólico a fin de comprender el proceso de asignación de símbolos con significado que se le otorga a la lengua hablada o escrita y al comportamiento en la interacción social. (Araya, 2007, citando a Blumer, 1996).

\section{Técnicas}

La principal técnica que se utilizó fue el conversatorio, propuesto en el CCRISAC, dando como resultado un diálogo que asegura la transmisión de conocimientos y sabidurías de manera intergeneracional através de la palabra. Esto resultó factible en los diferentes espacios, ambientes vivenciales y cotidianos de la comunidad, así como las ceremonias y ritualidades que se desarrollaron en la comunidad Fruta de Pan para retroalimentar la enseñanza para la cosecha.

Los conversatorios se ampliaron al campo, en momento en que la comunidad trabajaba la tierra, tareas de las cuales fuimos parte para la construcción del pensamiento colectivo. Asimismo, se utilizaron entrevistas con preguntas guiadoras de las conversaciones realizadas, y, un diagrama de palabras cables, las que guiaron las pláticas.

\section{Estrategia del muestreo}

En primera instancia se indagó quienes son las y los ancianos de la comunidad, para proceder al proceso de identificación de las personas de la comunidad con las que se hizo las conversaciones de saberes.

Seguidamente se combinaron los procesos de recolección y análisis de datos y se continuó hasta llegar a la saturación teórica, en donde por más que se regresó al campo y se analizó nuevos datos no aparecieron nuevas categorías. 


\section{Procesamiento y análisis de la información}

Se caminó en base al proceso epistemológico de comprensión, síntesis, teorización y recontextualización. Cuatro procesos que corresponden a una secuencia lógica, ligada al progreso de elaboración mental que el investigador cualitativo desarrolla en el transcurso de su labor de creación de conocimiento (Castillo y Lee, 2009, citando a Duriez, 2007, p.83).

Se procedió a transcribir cada conversatorio y entrevista de manera que se consiguiera visibilizar las respuestas a las preguntas directrices del cultivo y crianza, lo que posibilitó analizar palabra clases, repetidas, las opiniones y los discursos vertidos desde diferente formas, pero aludiendo a un mismo mensaje.

En el contexto de lo aquí establecido, se efectuó la teorización, por medio del cual se construyeron explicaciones alternativas, apoyándose, para ello, en la lectura e interpretación sostenida de los datos generados por la investigación.

\section{Consideración Éticas}

Las consideraciones éticas que se tomaron en cuenta para este estudio son:

- La información que los comunitarios y comunitarias proporcionaron es estrictamente confidencial.

- El alcance del estudio no da para generalizaciones.

- Los datos obtenidos son con fines académicos.

\section{Resultados y discusión}

\section{Los saberes ancestrales}

Las y los indígenas Sumu-Mayangna de la comunidad de Fruta de Pan, viven sus saberes ancestrales, producto de una experiencia milenaria de hombres y mujeres que a través del contacto directo con la naturaleza aprendieron a entender los mensajes de la Madre Tierra.

La experiencia del grupo explorando la tierra les permitió saberes sobre los espíritus que habitan y cuidan cada espacio de la tierra, encontrando espacios sagrados y dimensiones. Asimismo aprendieron el cuido y preservación de la naturaleza, así como la relación armónica con los espíritus. Las y los participantes del conversatorio exponen que otro de los saberes de sus ancestros, es estar atentos a los símbolos naturales. Conocimiento que les permite entender que está pasando y estar alertas para accionar con anticipación ante cualquier evento natural. 
Los saberes ancestrales, encierran todas las formas de comunicación con la madre tierra, porque son adquiridos por el compartir milenario, bajo el cielo, sobre la tierra y rodeados del agua en los ríos, que también es la vía de transporte para las y los indígenas en la Costa Caribe de Nicaragua, además donde está el alimento y por supuesto el vital líquido para la vida.

De modo, que en el conocimiento del pueblo sumo-mayangna, la madre tierra posee tiempos para quedar embarazada y dar a luz los frutos, es entonces la capacidad de observar el comportamiento de la tierra. Una virtud del conocimiento ancestral sumu-mayangna es que les permite cuidar el hábitat y alimentos de los seres vivos.

Lo antes planteado es coherente con lo que expone Muñoz y Romero (2010), que los conocimientos de una vida espiritual en la naturaleza y la lecturas de los símbolos son parte de las sabidurías de los hombres y mujeres, de los saberes, conocimientos y prácticas encarnados en cada uno, construida en su relación íntima y continua con la Pachamama-Madre tierra.

Estos saberes ancestrales le han permitido al pueblo sumu-mayangna, crear su propio calendario del año, que no tiene una lectura numérica sino por los ciclos de la vida y reproducción en la tierra. Por ejemplo, la temporada de siembra y cosecha de arroz, así como los tiempos sagrados para la reproducción de los animales, momentos en los que no se les puede cazar, pues se respeta su crecimiento, cerciorándose de que tanto los animales como los frutos que consuman estén aptos, para no romper con el equilibro natural. En una comunicación personal Patterson (2016), expresó:

"Se toma solo lo necesario para el alimento de la comunidad y de las numerosas familias, se siembra tres veces al año y el alimento está fresco, nunca se comercializa, porque se comparte y se intercambiaba. Recuerdo las enseñanzas de mi papá, cuando salíamos a veranear y eran varios días en la vega del rio, él no, nos dejaba encender fuego en el pie del chilamate, la fogata había que prenderla largo, de manera que el humo no dañara ni sus hojas, ni las raíces, porque el chilamate conserva el agua y también es alimento para los peces, siempre dormíamos entre las gambas, pero se tomaban todo tipo de cuidado, para que su espíritu no se enfadara".

Estos saberes ancestrales como forma de comunicación propia, son la evidencia de que el pueblo originario, llevó lo intangible a tangible. Proveyéndose de todas las habilidades para la vida plena y natural con todos los requerimientos para que se formen cada vez más mujeres y hombres sabios con actuaciones coherente a sus saberes que perpetúen estas prácticas. Esta representación de comunicación es inherente al pueblo indígena Sumu-Mayangna, por lo que muestran total familiarización con este escenario, que tiene dentro sus aspectos; contenidos espirituales y culturales abarcadores de todos los aspectos de la vida, sustraídos de un sinnúmero de años de experiencia adquirida por la convivencia con la tierra. 
Sin embargo, existe preocupación por parte de los ancianos de la comunidad que gira entorno a la poca transmisión de estos saberes a las nuevas generaciones. Lo que debe ser prioridad para pervivir en el tiempo como pueblo, como una colectividad políticamente constituida.

\section{Comunicación Espiritual}

Los misterios y secretos de un mundo anímico fueron dispuestos a los caciques, encargados de la comunicación con espíritus, para ser dirigidos por estos y gobernar a las y los sumu-mayangnas con sabiduría. Ese diálogo continúa y la credibilidad total en los espíritus les da el poder de tutelar los caminos para la vida de las personas de la comunidad. Esta práctica comunicativa consiste en el cuidado de la naturaleza a través de la convivencia armoniosa con los seres místicos, guardianes de la tierra.

La historia de los sumu-mayangnas cuenta de luchas espirituales que se libraban de reino a reino por causas diversas. Existían ocasiones que el bando contrario lanzaba un conjuro de gran magnitud que podía exterminar un poblado completo. La comunicación de los espíritus con el cacique era necesario porque ellos, lo ponían sobre aviso y este podía contrarrestar el maleficio con otra evocación para destruir los maleficios en el aire antes que tocara tierra. Lo que se puede apreciar en la siguiente expresión de uno de los entrevistados:

"Los caciques Kaukabin, sumunayny, usaban a los espíritus para gobernar y movilizarse a través del río, en el caso del cacique Kaukabin se montaba en un lagarto y sin mojarse salía a Rio Coco, allí estaban esperando, las comunidades hermanas y hacían asambleas de tres a cuatro días".

El pueblo sumu-mayangna de Fruta de Pan, cree que existen dimensiones espirituales en la Madre Tierra, donde hay información que es retomada y transmitida en un estilo de vida a los hijos e hijas. Donde se fomenta el respeto a la naturaleza y a los recursos de los cuales se subsiste, además existe el temor a ser castigados por los dueños o protectores de los animales al accederse en la caza o pesca. $\mathrm{Al}$ respecto mencionaron los y las comunitarias:

"Hay espíritus en la naturaleza que llegaron a la tierra antes que cualquier ser humana, así que los sabios solían decirnos a donde no debíamos ir a trabajar y adonde no se podía tocar. Por ejemplo los árboles de ceiba, tienen un dueño espiritual, los niños no deben pasar solos cerca del árbol y por la noche ni las personas adultas pasaban, porque el espíritu dueño podía enfermarlos, le agarra calenturas fuertes y parece como que le va a dar un derrame, si lo llevan al hospital la cura no llegan, solo quien practica la medicina ancestral puede curarle". 
Lo antes planteado es coherente con lo indicado por García (2014), Chuji (2007) y Agurto y Mescco (2010), quienes confirman la existencia de personas que se comunican con los espíritus y aseguran que estas personas son escogidas por los dioses supremos de la naturaleza, la que es el centro de todo y es la parte más importante del universo: observa, comprende y comunican las buenas voluntades o sus desagrados y que los chamanes interceden ante el mundo sobrenatural y el humano, por tal motivo, se les considera como los sabios y sabias especialistas en comunicarse con otras realidades $\mathrm{u}$ otras dimensiones de diferentes maneras.

Por esto es posible afirmar que la convivencia armónica con la naturaleza que aún vive el pueblo mayangna es producto de los aprendizajes espirituales adquiridos a través de la experiencia que heredaron de sus ancestros. Esta comunicación fue posible por actos de creencias forjadas con saberes e ideologías de valor, amor, respeto y la capacidad de dar y recibir de la madre tierra con la creación de un vínculo entre los hombres, las mujeres y su espacio natural. Es evidente que los comunitarios continúan viviendo bajo las reglas que fueron transmitidas cuando aún las personas se comunicaban continuamente con los espíritus y estos les enseñaron a proteger la tierra.

\section{Comunicación a través de los Sueños}

En la cultura sumu-mayangna los sueños marcan sucesos importantes de sus vidas. Para ellos y ellas existe un proceso cognitivo sobre la presencia de alguien que les cuida y usa este medio para comunicarse, previniéndoles de peligros como una madre a sus hijos e hijas y en ocasiones les llena de regocijo interno para esperar buenas noticias.

En conversatorios realizados con comunitarios y comunitarias estos manifestaron haber tenido sueños que les llenaban de alegría, porque en los sueños veían la bonanza de lo existente en la Madre Tierra.

"Si en mis sueños yo pescaba un guapote, significaba que eran hijos hombres los que iba a tener mi esposa, la única vez que en mis sueños pesque una guabina, nació mi única hija mujer, ahora que estoy viejo y mis hijos están grandes, soñé una pesca abundante, en ese año todos mis hijos me hicieron abuelo".

Según las experiencias compartidas se evidencia que los sueños son un medio comunicativo que emiten mensajes con imágenes y símbolos desarrollados. En el transcurso del sueño se pueden escuchar voces y sentir diversas emociones como: alegrías, tristezas, enojo, miedo y ansiedad, estas pueden provocar deseos de continuar ese momento o despertar, pero también son esos mismos sentimientos que llevan a la persona a desear saber el significado del sueño. 
Las personas que saben leer o interpretar los sueños son sensibles, consideran los procesos de la mente como armónicos y desarrollan sus teorías a un llamado a cuidarse durante el día siguiente al realizar una misión o a esperar bendiciones.

Los sueños traen diversos mensajes a las personas, lo que coincide con lo que expresan Agurto y Mescco (2010) también por (Gutiérrez et al., 2015) y Veughan-Lee (2015) que soñar no es un hecho que carece de significado y significación, sino que es una forma de comunicarnos con los espíritus de la naturaleza y/o de los ancestros. Al interpretar los sueños se encuentran personajes del interior llenos de sabiduría, porque hay lenguajes internos esperando a ser redescubiertos. Por lo que en un sueño encontramos nuestro camino individual en el mundo y realizamos un andar atentos y alertas, para responder a las necesidades de los demás.

El pueblo sumu-mayangna continúa creyendo que los significados de los sueños los preparan para cada momento de la vida. Compartirlos en la comunidad es estar informados y a esperas de los acontecimientos venideros. De acuerdo con la recolección de los conocimientos sobre los sueños es posible afirmar que en estos hay dos tipologías de mensajes: uno que lleva al soñador/a a actuar de inmediato, y otro que llama a la acción con plazos indefinidos, en este último caso, se entiende la acción como la realización de una misión futura a beneficio de la comunidad.

Cabe mencionar que estos sueños se hacen presente en un contexto adecuado a la vida de cada individuo o grupo social. En muchos de los casos, se presenta una realidad en la que aparecen otras personas llevando una misión, como si hubiesen vivido experiencias en otra vida u otra dimensión.

Según lo observado en la comunidad ya no se toma a los sueños con la importancia que estos tienen como forma de comunicación. Debido, a la influencia de la iglesia y su evangelización, que ha declinado el interés por los saberes de los sueños, y porque se hace evidente que la mente de los más jóvenes no está lista para adquirir estos conocimientos. En todo caso, existe temor de hablar de estos temas.

No obstante, la Madre Tierra no ha dejado de comunicarse, pero son pocas las personas de la comunidad que están dispuestos a escucharla. Otra de las realidades es que por conocimientos transmitidos de generación en generación, creen que para cada sueño ya hay una predicción así que no es necesario consultar a un lector o lectora de sueños, en otras palabras se ha dejado de buscar entender los nuevos mensajes que están siendo emitidos en los últimos años.

\section{Arte tradicional comunicativo}

Para este pueblo la destreza del arte le permitía la asignación de una identidad individual en el grupo. Por ejemplo si manejaba a la perfección el arco o flecha era llamado 
como el hombre buen arquero o flechero, si tenía la destreza de correr más rápido que un venado era llamado el hombre ligero. Especializarse en alguna actividad era esencial para los antepasados de este grupo étnico. Antropológicamente se llama arte primitivo, en primer lugar estaba ligado a creaciones usando lo que le ofrece la naturaleza para desarrollar una vida sencilla y armoniosa con tierra, en segundo lugar porque son conocimientos transmitidos por sus antepasados y se mantiene la práctica de generación en generación.

El arte sumu-mayangna está basado en el acondicionamiento del espacio donde vive. Por ejemplo, entre las prácticas culturales, es que los hombres antes de pedir la mano de su futura esposa, debían construir la casa y elaborar las ollas que usaría su compañera, ellos que son apreciadores de la belleza natural impregnan en su arte lo que observan.

"En la naturaleza esta nuestra casa, nuestro alimento y los conocimientos, en ella está la medicina, en ella está la alegría, nosotros somos hechos de ella, y utilizamos las hojas para hacer los techos y los bejucos para amarrar"

Es un orgullo para algunas familias autóctonas de la comunidad de Fruta de Pan, mostrar la sutak, es una pana muy bien elaborada con el fruto del árbol llamado jícaro, un invento milenario con el que se comparten los alimentos. "La Sutak, bendice nuestra bebida, el agua es más fresco y se mantiene así hasta que la tomamos".

Otra de las creaciones artísticas del pueblo sumu-mayangna, es el pilón utilizado junto con los pisones, para pilar el arroz. Cada familia tiene su propio pilón, es muy característico de las personas de cada hogar. El tallado de los pilos es a mano, para lo que es escogido el árbol de madura más fuerte y grueso.

En relación a esto, Gonzáles (2004) y Pérez y Merino (2014), manifiestan que el arte no pretende agradar a nadie, es expresión, es pensamiento visual, no está hecho para consumirse, más allá de su función social, porque es un vehículo que permite expresar o reflejar la cosmovisión de una persona, a través de los manifestaciones artísticas, el sujeto plasma su representación del mundo y sus valores, por lo que la calidad de su producto está hecho para alguien con rostro, para un ser querido o respetado, para los dioses, para los antepasados, para honrar la tradición del amor a la tierra.

De acuerdo con lo observado, existen personas muy buenas con el arte de dibujo. Sus principales obras muestran la belleza de la naturaleza y lo que existe en su comunidad. Estas obras no son vendidas solo son para embellecer algunas casas en la comunidad. 
Otra de las artes ancestrales que fue posible observar es la construcción del bote. El que es elaborado de un árbol, arte transmitida de generación en generación, ya que viven a la orilla de los ríos y se vuelve un medio de transporte.

En síntesis, el arte tradicional de las y los habitantes de Fruta de Pan es una forma de adoptar la vida a una manera de proteger la naturaleza ya que su arte no es negociable. El arte que practican las personas de la comunidad tiene la popularidad de ser usado por las mismas personas que lo crean, es elaborado con las facilidades que le brinda la naturaleza y para ser usado en las acciones de cada día, este arte evidencia la aceptación de las orientaciones de la tierra.

\section{Gastronomía "comida propia"}

Los hombres y mujeres sumu-mayangnas que protegen la Madre Tierra son personas creyentes en que su forma de alimentarse es un arte. En este contexto, a lo que se conoce como gastronomía ellos y ellas optan por llamarle comida propia, porque afirman que su alimentación es sana, nutritiva y sin químicos que producen efectos secundarios en el cuerpo humano.

El pescado que tiene un gran valor nutritivo, proporciona proteínas de calidad, múltiples vitaminas y minerales, la carne de animales silvestres, los bastimentos como banano, la yuca y el quequisque, sin dejar de mencionar el consumo de frutas de cada temporada que proveen la mayor cantidad de nutrientes y sustancias naturales altamente beneficiosas para la salud, son la tendencia de su dieta alimenticia.

Las y los mayangnas se caracterizan por saber con exactitud dónde están los animales que se pueden cazar, leen en la naturaleza cuando la madre tierra les está entregando un fruto en su tiempo exacto de comer. Esto les permite acceder a una alimentación que no altera el proceso de crecimiento, ni reproducción de las plantas y los animales, pero sobretodo garantiza una alimentación adecuada. Asi lo confirma otra de las entrevistas:

“Cuando era niña recuerdo que me gustaba seguir a mi mamá, a ella le gustaba recoger esas frutas del kerosín y comíamos, aprendí de ella muchas cosas, qué comer y qué no, para no contaminar nuestro cuerpo o nos hagan daño".

Lo antes expuesto tiene lógica desde lo planteado por Delfin, (2009), al referir que la gastronomía es el arte intangible al preparar una buena comida. Esto por consiguiente, hace alusión a un arte que va más allá de los objetos de uso cotidiano y que han sido elegidos para representar las costumbres de una sociedad en un momento determinado de su historia, como por ejemplo, la ropa, los instrumentos de carpintería, las armas, la comida, entre otros. 
De esta manera, el arte de la comida propia está dada a esa comunicación diaria de él y la indígena en su huerta, evidenciándose una ritualidad que conjuga y hace converger producción con perseverancia en el que la familia que produce muestra sentimientos como el amor y respeto por los cultivos que produce y que culmina en el momento de la cosecha y el consumo.

Al hacer observaciones respecto a esta forma de comunicación con la madre tierra, permitió saber cómo preparan sus alimentos. La mayoría de los alimentos son solo cocidos como el quequisque, que es esencial en la dieta alimenticia de las personas mayangnas. Es preparado de manera totalmente natural, sin grasas, azucares o sal, y es dispuesto de diversas formas.

El arte de la comida propia, desde su siembra hasta su preparación y consumo. Es una forma de comunicar que la madre tierra merece respeto, cariño y protección que es posible nutrir el cuerpo con lo que sale de sus entrañas. Esta es una manera de dar y recibir, es posible deducir que en esta práctica se da lo que se conoce como comunicación horizontal. Es evidente que la semilla puesta en la tierra, según la fe de las y los indígenas, para que su fruto sea bueno es un sentimiento percibido por la tierra, la que responde y el productor sabe cuál es la respuesta, dependiendo de la calidad del fruto recogido.

Este proceso se repite muchas veces, los cultivos están destinados al sustento y hay una comunicación directa con la tierra. A través de la observación también fue posible ver que este proceso no ocurre en los huertos de personas que no tienen esta armonía. En la forma de comunicación de la comida propia, se da una protección recíproca porque la tierra cuida también a quienes consumen sus alimentos, porque la envoltura de cada fruta o grano es natural y no tiene tóxicos, se desprende caen a la tierra y esta los recibe una vez más, satisfecha de haber alimentado a sus bebes.

También las y los funcionaros de instituciones que viven en la comunidad, no están sembrando la tierra, por tanto están comprando los productos procesados, empacados y embutidos, de tal manera que ya se puede observar en la comunidad la acumulación de plásticos, botellas y empaques que no son recibidos por la tierra.

\section{Práctica cultural lingüística}

La cultura de este se forma en base a los hechos y es posible entenderla gracias a la historia. Así es que nos remontaremos a los años 80 tiempo de guerra en Nicaragua, cuando los habitantes de Fruta de Pan que estaban asentados río arriba del Bambana, donde actualmente es Dibahil, se vieron obligados a habitar en el lugar conocido como la granja, porque hombres armados se posicionaron de esta parte del territorio alegando que es más alto y les da mayor visibilidad, acción que ponía en peligro a la comunidad. 
Esto ha conllevado a un proceso de adaptación hasta el punto que actualmente las familias están compuestas por personas mayangnas y misquitus, fusionando de esta manera las dos etnias y con ello, incorporando una variación en la forma de vivir y de relacionamiento con la naturaleza. Esto ha traído consecuencias negativas en el uso de la lengua mayangna ya que ha prevalecido la lengua misquitu. Con respecto a esto un joven reflexionó:

"Ahora un 99 por ciento de los pobladores hablan miskitu, mi mamá y papá son mayangnas, pero como todos hablan miskitu entonces se comunican así, hasta ahora que soy profesor entiendo que debemos hablar mayangna y he pasado tiempo preguntado a mis padres para recordar, y digo hablen con mis hijos esa lengua, para que ellos la puedan hablar".

El pueblo sumu-mayangna se enfrenta al fenómeno conocido como la transculturación que de acuerdo a De Magdalena (2010), es la recepción que un pueblo o grupo social hace de las y formasude cultura procedentes de otro, que sustituyen de un modo más o menos completo a las propias. De acuerdo con lo observado la transculturación que sufren las y los sumu-mayangnas de esta comunidad, afecta también la identidad individual y colectiva ya que son familias mixtas donde predomina una de las culturas. Uno de los entrevistados expresó:

"Yo tengo dos hijos, uno parece mayangna y el otro no, pero yo creo que eso depende de lo que le digan los padres, porque su mamá le dice que son miskitos, y los dos se sienten y se identifican así".

Otro de los conflictos en razón de la identidad cultural lingüística, se produce en el debate de ser sumus o mayangnas. Esto debido a que el nombre original es sumu, pero al preguntarles cómo se identifican, sus rostros sonríen y parecen repensar su respuesta, como una expresión de protesta tras el nombre de mayangnas.

Para los ancianos y ancianas la palabra Sumu significa personas "fuertes", "ligeros" porque así se caracterizaban sus antepasados, guerreros fuertes que experimentaron una y otra vez su agilidad mientras cazaban. Los más jóvenes respondieron "dueño", expresando que son dueños de la tierra, porque ellos saben cuidarla.

En la cosecha de los saberes sobre la práctica cultural lingüística se encontró que no es una forma de comunicación propia para la defensa de la madre tierra, debido a la pérdida parcial del idioma como parte de la identidad cultural. Sólo los ancianos y ancianas conservan la lengua pero esta no es practicada a nivel de la colectividad ni con los jóvenes. El idioma misquitu es el que prevalece y es al que se le da la importancia como vehículo para el aprendizaje de la segunda lengua, el español. 


\section{Manifestaciones de procesos de comunicación propia para vivir en armonía con la madre tierra}

La comunicación sobre la Madre Tierra, ha generado una práctica tradicional milenaria del pueblo sumu-mayangna, lo que les ha permitido describir a la tierra como una "mamá" que da a luz, cuida, alimenta, y sobre todo, es garantía para la vida y no para el dinero.

Los conocimientos necesarios para la vida humana provienen de la tierra, así es afirmado en la cosmovisión de esta cuna de gente sabia. Desde sus antepasados vivieron grandes dificultades para preservar la vida humana, lo que les llevó también a entender a la naturaleza como la única salvaguarda de su existencia.

Contemplado de esta manera, que la montaña es el lugar donde la madre sirve su comida a sus muchos hijos e hijas, les provee de medicina y lo necesario para que construyan sus resguardos, el agua de los ríos es la leche que emana de los pechos de las madres, que son los cerros llenos de árboles, de allí su importancia.

Es parte de la cosmovisión sumu-mayangnas, que los árboles, los cerros y los ríos tienen dueños. Son duendes que viven en cada uno de ellos y si las personas no hacen uso con el debido respeto que se merece, se enferman hasta el punto de causarles la muerte si la o el conocedor de medicina tradicional de la comunidad no le da tratamiento. Esto lo refiere otro entrevistado:

"Eso es auténtico, no es mentira, las personas de antes no se enfermaban porque sabían bien todo esto y lo respetaban, por ejemplo, si el papá viene de la montaña no tiene que agarrar al niño porque puede traer espíritus malos y nosotros debemos hacer un humo y sahumamos, para que el espíritu no se lleve el niño".

El pueblo sumu-mayangna, replantea la vida después de haber sido nómadas, esto fue el comienzo para poner en práctica todo lo que hasta ese momento habían aprendido. Todos los aspectos comunicativos con la tierra les permitían saber que esta otorga a sus hijos e hijas un espacio adecuado que no podrían invadir los espacios naturales. Armonizaron con los espíritus y se asentaron en un área donde formaron la comunidad, donde han vivido por muchos años. Así lo explica uno de los entrevistados.

"Nuestros ancestros no se equivocaron, si ellos nos enseñaron que la tierra es comunal es así y la podemos ayudar y cuidar mientras la compartimos, esa es una práctica que nos permite ser más hermanables y no dejar que la ambición se apodere de nuestros corazones". 
Sus políticas y sus relaciones sociales están basadas en el cuido de todas las personas de la comunidad. Los hombres y las mujeres cuidan las huertas propias y las de sus vecinos, si el hombre de la casa está enfermo unen sus fuerzas para ayudarle en el proceso de la parcela, si la mujer está enferma todas las demás mujeres buscan las estrategias de ayuda, de esta manera ninguna actividad de la comunidad se detiene.

Las nuevas familias que se forman son solidificadas con base a esos conocimientos. Es responsabilidad del hombre las prácticas que manifiesten que toda la naturaleza es sagrada y solo se toma de ella lo necesario para vivir. Si la ambición llega al corazón del hombre, los espíritus le provocarán enfermedad a la familia. Uno de los entrevistados manifestó:

"Cuando pensé en hacer la casa para la familia, me puse a ver dónde y me gusto este lugar, pero a los días de habitarlo, mi niño enfermó, daba gritos de espantado por un animal que le daba miedo, entonces mi papá llamó a la señora que cura y ella hizo medicina, me dijo que el viejo de la montaña se estaba llevando a mi hijo, que ya me estaba dando de comer y que estaba molesto porque vine al cerro a vivir".

Este relato concuerda con Pérez y Merino (2014), al referir que la cosmovisión se fundamenta en su relación con la madre tierra y la naturaleza, sabiendo leer las señales del clima, conocer los secretos de la tierra y las montañas, respetar y aprender de la selva, sacar agua de los desiertos y las zonas de conservación.

De acuerdo con lo observado, los resultados de los conversatorios y la convivencia, la cosmovisión del grupo indígena de Fruta de Pan, es realmente una manifestación de la experiencia comunicativa con la madre tierra a través de todo lo existente en ella. Es evidente que no fue fácil alcanzar ese nivel de entendimiento de todo el entorno natural. Se puede determinar que el desarrollo de la espiritualidad es la clave de las cosmovisiónes y que la Madre Tierra es el libro más antiguo que tiene la humanidad para aprender de ella.

Otra manifestación de la comunicación propia para la convivencia armónica con la madre tierra, es la danza, donde se toma como referencia el comportamiento de los animales para entender lo que está pasando en la madre tierra. La danza originaria es una manifestación de la comunicación propia en sus diversas festividades, se realizan presentaciones que muestran la alegría de los animales, en momentos como cuando la lluvia cae y moja la tierra.

Son danzas que entretejen la relación y la comunicación con la gente, la rueda durante el baile es la expresión de la convivencia en la comunidad. Durante la danza se vivencia una alegría colectiva donde todos ríen y hablan, pequeños y grandes disfrutan cada paso y cada mensaje. Posterior a cada presentación, llegan los espacios de comentarios de las experiencias que les ha tocado vivir. Los instrumentos músicales 
que acompañan las presentaciones (pequeños tambores y pitos) son elaborados a base de bambú.

Por ende, y siguiendo a Delfin, (2010) y UNESCO (2012b), la danza es el vínculo que se establece con las fuerzas sobrenaturales y con los dioses del grupo en cuestión. Las comunidades indígenas danzan por una manifestación de los saberes obtenidos de la madre tierra. Por ejemplo, la danza de los sapos que anuncian el invierno croando y saltando, es señal que llegó el periodo de siembra (entre abril y mayo). Para nuestros ancestros significa esperanza, renovación de la vida, buenos tiempos, abundancia y fertilidad.

Lastimosamente, en la actualidad las danzas ya no se realizan con periodicidad debido a las influencias externas que llegan a la comunidad, como la iglesia. Una de las danzas ya desaparecidas es la de sanación, desde donde se invocaban a los espíritus para curar a las personas. Esta no es practicada ni recordada desde hace más de ocho décadas por lo que ha desaparecido totalmente.

Una de las grandes batallas que enfrenta el pueblo Sumu-Mayangna es la lucha por mantenerse unidos y por preservar los saberes propios. Muy importante ha sido conservar la tranquilidad, evitar los conflictos, habitar en armonía con la Madre Tierra, pero si ella está amenazada, también lo está la comunidad. La resistencia indígena ha empezado con las diferentes organizaciones creadas para velar por el bienestar de la comunidad. De esto habla la siguiente entrevista:

"Sukawala tenía diferentes asignaciones para las parteras, para los curanderos, la cultura desde donde se contaba cuentos y se contaba la historia"

Lo anterior, concuerda con Arrobo (2005), que para mantener la vida, las identidades colectivas y los valores comunitarios, los pueblos deben resistirse a ceder su territorio y su cultura, igual, cuidar los espacios de comunicación indígena porque es constitutiva del sujeto social indígena y de sus expresiones simbólicas.

La resistencia sumu-mayangna como una manifestación de la comunicación con la madre tierra, en la actualidad tiene mayor demanda y exigencia porque su vínculo que los mantenía unidos para protegerse, parece estarse disolviendo por los factores de clasificación social a la que han sido sometidos.

Las y los comunitarios están preocupados por este panorama, porque en la lucha de la resistencia esta problemática los debilita. Expresan que el gobierno territorial Tuahka, dejó de impulsar proyectos destinados a la resistencia y pervivencia del espacio territorial y cultural, y al contrario, prevalece el mal espíritu del individualismo y los antivalores, por lo que luchan por controlar situaciones que no los fraccione y atenten diariamente con la unidad. 
Desde la perspectiva del pueblo sumu-mayangna, el espacio territorial de Fruta de Pan, nunca se había visto tan amenazado como en estos últimos tiempos, por los procesos de compra y venta ilegal de la tierra. Este es un fenómeno que ha afectado a otras comunidades como Wasakin, donde algunos indígenas vendieron sus tierras.

A finales del 2015, la comunidad de Wasakin ya había perdido totalmente su bloque territorial. A inicios del mes de junio del 2016, la comunidad Fruta de Pan, se entera que en sus espacios de reserva ya estaban siendo habitados por personas a la que ellos llaman colonos, situación que alarmo a los comunitarios.

Las autoridades comunitarias de Fruta de Pan, han solicitado ayuda externa pero no se ha podido obtener una respuesta a la problemática, lo que dificulta vivir en armonía y paz en la comunidad y en los sitios sagrados. De acuerdo con lo observado la venta de tierra es una situación que tiene desesperados a las y los indígenas y la mayor prueba de defensa de la tierra a la que deben enfrentarse.

Otra de las maneras de comunicación intergeneracional son las leyendas que son contadas entre las personas sumu-mayangnas, exterioriza los enigmas y las maneras misteriosas de comunicación que tiene la tierra. En estas se muestran las prohibiciones para quienes habitan en ella, y las bendiciones recibidas, para quienes desarrollan una vivencia armónica con el medio ambiente.

Cada atardecer en el corredor de las casas donde se reúnen las familias, es posible apreciar las tradiciones comunitarias de Fruta de Pan, como el momento de las leyendas que llega con la conversación con los más pequeños del hogar. Las leyendas narran la acción y valentía de hombres fuertes e inteligentes, ayudados por los espíritus de la naturaleza, capaces de dominar el peligro que les asechaba. Otros relatos, hacen alusión a personas desobedientes de las reglas construidas sobre la base de la sabiduría ancestral en la comunidad y por ende, señalados de provocar una ruptura en el equilibrio del entorno.

"Cuando mis hijos eran pequeños, conversaba mucho con ellos y mientras limpiábamos los siembros allí les contaba de nuestras vivencias inexplicables”.

Lo expresado por las y los comunitarios es elocuente con lo planteado por Jarquín y Moreno (2014), cuando refieren que la vivencia con la madre tierra a través de la espiritualidad permite a las y los indígenas que aparezcan las leyendas. Las mismas son parte de las enseñanzas y aprendizajes en el uso y relación con la Madre Tierra, la historia y las creencias de los pueblos.

Según los resultados del conversatorio, las leyendas de los sumu-mayangnas, en su mayoría son reales y contadas de generación en generación. También afirman que en base a éstas, algunas personas han vivido experiencias con muchas similitudes 
las que corroboran la autenticidad de las leyendas de los antepasados. El siguiente testimonio recoge una gran vivencia:

Cuando yo escuchaba esas historias algo en mí decía no creo, pero un día me fui al rio, pesque y cuando venía, mire un montón de gallinas de monte y mate tres, aquél parecía mi día de suerte, un hermoso venado se me cruzó en el camino, yo caminaba listo siempre y sentí fácil matarlo también.

Cuando ya venía cerca se me ocurrió llevar yuca, puse todo en el camino y me metí a sacarlas, ya de regreso, de repente sentí como que me desperté y me di cuenta que había caminado bastante y comencé a preocuparme porque estaba seguro que había dejado la carga bastante cerca, en ese momento decidí caminar con rumbo a la casa y luego volver por la carga, pero no podía, era como si la montaña me cerrara el paso.

De repente me acordé de los cuentos de mi mamita, en los que hombres de la comunidad se perdieron en la montaña y me dio mucho miedo, porque ella decía que eso pasaba cuando uno lleva más de lo que necesita para su familia, fíjese que escuchaba a los chavalos jugar en el patio de la casa pero no llegaba a donde estaban ellos. En ese momento solo puse las rodillas en el suelo ya que me sentía sin fuerzas de tanto caminar y cerré los ojos, cuando vi estaba a dos pasos del patio de la casa, fue tan increíble lo que me paso que hasta no regrese por la carga.

Según lo observado, el hecho de compartir las leyendas ancestrales son prácticas que están perdiendo vigencia en la actualidad. Aunque existen ancianas y ancianos con voluntad de contarlas, la juventud prefiere ver la televisión utilizada por un 80 por ciento aproximado de las casas de la comunidad. Esto pone en peligro los saberes ancestrales que se transmiten a través de esta metodología autóctona.

Las personas de la comunidad ven que las prácticas están cambiando y piensan que es difícil obligar a los jóvenes a ser como ellos pero que es necesario por el bien de su existencia y el fortalecimiento de su identidad. Exponen que deben buscar otros mecanismos que reactiven el interés por las leyendas como una labor extra curricular del docente de la comunidad. Apelan porque las y los jóvenes que salen a estudiar regresen a desempeñarse en la comunidad, a reencontrarse con ellas y ellos mismos en la vida comunal e implementen mecanismos innovadores para la vigencia de las leyendas del pueblo.

\section{Estrategias de revitalización y dinamización de las prácticas propias de comunicación para vivir en armonía con la madre tierra}

Descolonizar el pensamiento representa la oportunidad de revitalizar las prácticas propias comunicativas y continuar con la vida armónica con la Madre Tierra. 
Descolonizar el pensamiento de las y los indígenas Sumu-Mayangnas, de la comunidad Fruta de Pan es valorado como necesario, importante y trascendental, para continuar con el proceso de comunicación propia y para vivir en armonía con la madre tierra. Este es un contexto en el que es preciso crear, recrear, sistematizar, fomentar y vivir los conocimientos, saberes, prácticas y tecnologías ancestrales, y el fortalecimiento de la identidad como pueblo milenario.

Revitalizar y dinamizar las prácticas propias de la comunicación para la defensa de la tierra es promover la cosmovisión, arte, comida propia, espiritualidad, interpretación de los sueños y todos los saberes ancestrales, y esto solamente sería posible a través de un medio de comunicación masivo y económico como lo es la radio porque desde él se puede promover el rescate y el amor a lo propio. Por otra parte las y los autóctonos reconocen que para velar por su derecho a la tierra y preservar todas sus prácticas comunicativas que los guían a una vida distinta y armónica con la naturaleza, necesitan medios de comunicación masivos que permitan el debate público.

En la ciudad de Rosita, existe una radio universitaria de perfil comunitario que es escuchada por las comunidades indígenas, especialmente por Fruta de Pan. Las personas con las que se conversó expresaron que si bien en la emisora se identifican programas que financian el gobierno territorial Sumu-Mayangna, éstos no abordan ni contextualizan la realidad que se vive en la comunidad. Para uno de los entrevistados la radio representa oportunidades para estar en los procesos de la comunidad:

"Los abuelos pueden hablar con todos dentro de la comunidad, pero también ayudaría mucho si tuviéramos una comunicación en la radio, porque nos escuchan todos. Ayudaría a divulgar nuestras experiencias y nuestra comunicación con la Madre Tierra, asimismo sería bueno comenzar la alfabetización en lenguas en Mayangna".

Lo anterior, es coherente con lo expresado por Gómez (2013), y Chuji (2007), al referir que se hace necesario democratizar la palabra en una sociedad injusta. De allí la importancia en articulan desde las radios movimientos a favor de los derechos de los pueblos. Hoy por hoy, las actividades que se promueven desde la radio están dirigidas a la organización, la movilización social, la protesta, la defensa de los territorios, la interculturalidad y la lengua.

Mientras tanto, la exigencia también busca construir desde la participación comunitaria una programación personalizada por las organizaciones indígenas, dirigida entre otros temas a la revitalización de la identidad cultural y la autoestima de los pueblos y nacionalidades. Miremos lo que plantea uno de los entrevistados:

"Nos gusta escuchar que nos saluden por la radio, pero ayudaría a sentirse mejor si lo hacen en el idioma que yo entiendo, eso me gustaría más, pero sobre todo que me dejen decir sin que está haciendo mal para que todos busquemos soluciones". 
Otro de los aspectos urgentes a tratar es la pérdida de la lengua propia que está siendo desplazada por la misquitu, y esta última absorbida por el habla castellano. Las personas mayores de la comunidad comentan que solamente practicándolo es posible recordarlo y revivir la verdadera lengua sumu. Asimismo, valoran la necesidad de sentar las bases para la recuperación de la lengua, proponiendo un intercambio entre los jóvenes y los ancianos de la comunidad, que concluya con la creación de una escuela de saberes lingüísticos.

De acuerdo a las personas entrevistadas, una de las estrategias urgentes, ante esta situación es activar la enseñanza padres e hijos que asegura un proceso de aprendizaje compartiendo tiempos y haciendo actividades juntos, asi como implementando diversas modalidades de aprendizajes ancestrales dirigidas a promover la continuidad cultural del pueblo. Esta es una propuesta que eventualmente involucraría a las y los sabios, asegurando la retroalimentación de los conocimientos y derribando los estereotipos impuestos a sus prácticas ancestrales, para enseñar a comunicarse.

Mientras el diálogo fluía, se reconoció que ya nadie se dedica de manera específica a interpretar los sueños como una actividad indispensable en la manera que tienen de vivir, porque creen que los mensajes argumentan una realidad subjetiva. De alli, la importancia de rescatar esta acción como parte de la defensa y convivencia con la Madre Tierra. Con igual importancia, expresan que debería implementarse una campaña de sensibilización de rescate, revitalización y fomento de la cultura sumu-mayangna.

El debate también se detuvo en la práctica tradicional y la importancia de la comida propia. Una de las estrategias propuestas es la sensibilización para que los y las comunitarias que trabajan en las instituciones y no tienen tiempo para sembrar y cosechar alimentos, consigan implementar huertos familiares en el patio de la casa y así poder promover las prácticas ancestrales y los modos de aprendizajes en familia a través de actividades compartidas.

De acuerdo con los resultados es posible afirmar que los cambios en el pensamiento de las personas indígenas profesionales modifica también a la comunidad y según refieren los ancianos parecen desear olvidar sus raíces e ir en busca de otro tipo de bienestar o buen vivir. En este sentido, es importante volver a la comunidad pero con la mirada puesta en ella, en sus conocimientos, en sus prácticas, en sus saberes y en su plan de vida.

\section{Conclusiones}

Las prácticas comunicativas propias de la comunidad indígena sumu-mayangna están caracterizadas por la interpretación de los saberes espirituales, la comunicación con los espíritus para solicitar su aprobación de las tareas que realizan por el bien de la comunidad, y por promover una vida armónica con el entorno natural. Pese a esto, 
prevalecen pensamientos colonizados por el cristianismo que ha prohibido estas prácticas.

Sus bailes, formas de vivir y utilidad que le otorgan a las cosas que les provee la madre tierra son las manifestaciones de esa comunicación propia, que se representa en una convivencia amigable que demuestra la debida reciprocidad con cada espacio en la tierra, sus mito y leyendas como la vos de la historia que mantiene viva la fe en que existe vida y que nada mas se necesita defender el territorio, porque este no puede ser vendido y que sí es posible coexistir con los espíritus de la naturaleza.

Las acciones macros para lograr que las y los indígenas retomen su comunicación espiritual es la descolonización del pensamiento y el fortalecimiento de los conocimientos propios con el que se espera acabar con el temor inculcado por la doctrina cristiana, a hablar de las dimensiones espirituales. Asimismo, retomar la comunicación espiritual con los cuidadores de la naturaleza y evitar la venta del territorio.

\section{Lista de referencias}

Agurto, J y Mescco, J. (2004). La comunicación indígena como dinamizadora de la comunicación para el cambio social. Recuperado en: http://es.HYPERLINK «http:// es.slideshare.net/dikerd/alaic-comunicacinindigena2012-36203354»slideshare. net/dikerd/alaic-comunicacinindigena.

Arrobo, N. (2005). Sistematización de los resultados de los estudios nacionales de la investigación. Recuperado en: http://www.llacta.org.

Araya, J. (2007). El Interaccionismo Simbólico. Recuperado en: http://metodologiajose. blogspot.com

Castillo, L., y Lee, B. (2009). Impacto del proceso educacional en la carrera de Ingeniería Agroforestal, URACCAN Las Minas, cohorte 1998-2002.

Chuji, M (2007). Los medios de comunicación indígenas al servicio de los DD.HH. y colectivos. Recuperado en: http://www.alainet.org/es/active/16282

De Magdalena, A. (2010). Sincretismo el arte de resistir. Recuperado en: http://www. monografias.com

Gonzales, E. (2004). Arte, diseño y artesanía. La metáfora textil como signo de identidad. Recuperado en: http://fido.palermo.edu/servicios_dyc 
Delfin, M. (2009). El maíz, una planta de patrimonio cultural mexicano. Recuperado en: www.historiacocina.com/paises/articulos/mexico/maiz.htm

(2010). La Visión de la danza indígena ofrecido por Fray Toribio de Benavente Motolinía: La etnodanza mexicana y sus antecedentes al inicio de la época colonial. Recuperado en: http://HYPERLINK «http://www.ciberjob.org/etnohistoria/ danza.htm»www.ciberjob.orgHYPERLINK «http://www.ciberjob.org/etnohistoria/danza.htm»/etnohistoria/HYPERLINK «http://www.ciberjob.org/ etnohistoria/danza.htm»danza.htm

Gómez, C. (2013). Labor de la radio comunitaria. Recuperado en: http://carmenluci7. blogspot.com/2013/o6/labor-de-la-radio-comunitaria.html

Hernández, R., Fernández, C. y Baptista, M del P. (2015). Metodología de la Investigación. Sexta Edición. Mc Graw Hill Education.

Jarquín y Moreno (2014). Líderes Mayangna se pronuncian ante el comunicado de los obispos. Recuperado en: http://www.cisas.org.ni

Pérez, J. y Merino, M. (2010). Definición de cosmovisión. Recuperado en: http://definicion.de/cosmovisión/\#ixzz4Cdn38hkh

Muñoz y Romero (2010). Procesos comunicativos en la medicina ancestral andina, cantón otavalo-comunidad de kotama. Recuperado en: dspace.ups.edu.ec

Organización de las Naciones Unidas para la Educación, la Ciencia y la Cultura (UNESCO) (2012a). Cuaderno cultural sumu. La naturaleza está poblada de espíritus. Recuperado en: http://unicef.org.ni/media/publicaciones/archivos/6_Cuaderno_Culturl_Su

(2012b). Cuaderno cultural Sumu-Mayangna. Recuperado en http://webcache. googleusercontent.com/search?q=cache:wuOODaUzaAJ:

RUIICAY (2015). Documento Base para el Cultivo y Crianza de Sabidurías y Conocimientos - CCRISAC. Red de Universidades Indígenas Interculturales y Comunitarias de Abya Yala.

Veughan-Lee, L. (2015). Las señales de Dios. The Golden Sufi Center, Recuperado en: https://books.google.com.ni/books?isbn=1941394086 